Mohammed Mraoua, Driss Bari, Afrika Statistika, Vol.2, n¹, 2007, pp.22-43

Temperature Stochastic Modeling and Weather Derivatives Pricing :

Empirical Study With Marrocan Data

\title{
Temperature stochastic modeling and weather derivatives pricing: empirical study with Moroccan data
}

\author{
Mohammed MRAOUA * \\ Financial engineer, actuary \\ OCP Group, Casablanca \\ Driss BARI ${ }^{\dagger}$ \\ Meteorologist engineer (IMCL 1) \\ Maroc Météo, Casablanca \\ First version: October 2005 \\ This version: July 2006
}

\begin{abstract}
The main objective of this paper is to present a technique for pricing weather derivatives with payout depending on temperature. We start by using the Principle Component Analysis method to fill missing temperature data. Consequently, the cold and the warm periods were determined on the basis of a "clean" data by using a statistical approach. After that, we use historical data over a sufficient period to apply a stochastic process that describes the evolution of the temperature. A numerical example of a swap contract pricing is presented, using an approximation formula as well as Monte Carlo simulations.
\end{abstract}

Keywords: Weather derivatives, temperature stochastic model, Monte Carlo simulation.

JEL Classification: G13, C15.

\footnotetext{
${ }^{*}$ Corresponding author: Quartier Wahda, Rue 196, N 4778, Kénitra 37001, Morocco ; Phone: (+212) $67151967 /(+212) 74258472$; Email: mraoua@altern.org.

${ }^{\dagger}$ B. P. 631, C. P. 14000, Kénitra, Morocco ; Phone: (+212) 60078079 ; Fax: (+212) 22908635 ; Email: barid_ma@yahoo.fr.
} 


\section{Introduction}

The weather has a significant impact on several spheres of the economic activity. In fact, the weather risk management market has known an important growth since its inception in 1996. Although, the weather risk market got its start in the energy sector, other economic sectors such as retail and leisure are now starting to see financial benefits of protecting their revenue flows from adverse weather conditions.

The main objective of this article is to present a model to evaluate some derivatives with weather as underlying. The weather derivatives are financial contracts whose payout depend, on a certain way, on the climate. The underlying variables can be, for example, the temperature, the rainfall, the snow or the fog, but it is the temperature that represents the most used underlying for weather derivatives. In this paper, we will focus only on weather derivatives with temperature as underlying.

There are many factors which made the weather derivatives market developed. For instance, the liberalization of the energy sector. The energy producers had observed that the prices of energy are highly correlated with the weather. So, it was natural that the industrialists of energy cannot accept that their financial positions are at the mercy of a "bad" weather. The trading of the weather derivatives made possible to the energy companies to be covered against the weather risk.

In section 3, we will use the Principal Component Analysis (PCA) method which will allow us to fill the gaps in the series of the weather dataset used within the framework of this study. The identification of the warm and cold seasons at Casablanca will be detailed during this section. At section 4 , we will use a stochastic model to describe the temperature behavior. We will present within this framework a model from the family of Ornstein-Uhlenbeck processes. The unknown parameters of the process will be estimated with 44 years of daily temperature observations at the Casablanca meteorological station. Section 5 is dedicated to the pricing of a weather derivative contract with temperature as underlying. At the end, numerical results will be presented by using the Euler approximation formula and the technique of Monte Carlo simulation.

\section{The weather derivatives market}

The first weather derivative transaction was concluded between two American companies in 1997. Since, the market did not cease growing to reach 4500 contracts negotiated over the counter between April 2002 and April 2003. The weather derivatives market is still almost American and it is organized like all the financial markets. On one hand, the primary market is reserved to companies covering against weather risk (end users) through highly structured contracts and the sellers of these covers such as the insurers, re-insurers, banks and certain energy companies. On the other hand, the secondary market where the sellers of the covers negotiate between them standardized contracts which enable them to manage their weather books dynamically. The contracts treated on the primary 
markets can cover till several years and relate to different underlying such as temperature, rainfall, wind, height of waves level, snow, etc. On the secondary market, the contracts relate to the temperature and cover, in general, at least five days (from Monday to Friday), one or five months (period of heating from November to March and cooling from May to September).

Segments concerned and roles played by the distributors of the weather contracts, i.e. the energy companies, banks, insurers and re-insurers are very different. Indeed, in theory they are all capable to sell covers whose final payment is identically structured, the internal and external regulations to which they are subjected as well as the aim by their participation in this market make that they do not occupy all the same sector of the market. It is thus possible that the solutions suggested with a company eager to be protected from the climatic risks are different according to the contract organization seller (Cf. Moreno [24]). The OTC market of weather derivatives in Europe is starting to be developed. The French and English markets belong to the most active ones due to the implication of several banks and insurance companies. In Africa, the market of weather derivative is not developed yet except for some attempts in South Africa (Cf. Bhowan [8]).

\subsection{Definitions}

Weather derivatives are generally structured as swaps, futures and options based on different underlying of weather indexes. We present in this section some indexes usually used on the market of weather derivatives where the underlying is the temperature.

Definition (Temperature) Given a weather station, let us note by $T_{i}^{\max }$ and $T_{i}^{\text {min }}$, respectively, the maximum and the minimum temperatures (in degree Celsius) measured in one day $i$. We define the mean temperature of the day $i$ by

$$
T_{i}=\frac{T_{i}^{\max }+T_{i}^{\min }}{2}
$$

Definition (Degree-day) For a given site, the degree-day is the representative value of the difference between the temperature of a given day and a reference temperature. It is in general used to evaluate the expenditure in energy for the heating or air-conditioning. Let define $T_{i}$ as the mean temperature of a day $i$. We define Heating Degree Days $\left(H D D_{i}\right.$ : measure of cold in winter) and Cooling Degree Days $\left(C D D_{i}\right.$ : measure of heat in summer) by the quantities

$$
\begin{aligned}
& H D D_{i}=\max \left\{T_{\text {ref }}-T_{i}, 0\right\} \\
& C D D_{i}=\max \left\{T_{i}-T_{\text {ref }}, 0\right\}
\end{aligned}
$$

where $T_{\text {ref }}$ is the reference temperature (in general between $18{ }^{\circ} \mathrm{C}$ and $20{ }^{\circ} \mathrm{C}$ ). In the continuation of this paper "temperature" will mean "mean temperature". 


\subsection{The contracts}

In addition to contacts traded on organized markets (for example the CME of Chicago), there are also contracts which are concluded over the counter (OTC). One of the most used contracts is the option. There are two types of options, (calls) and (puts). The buyer of a HDD call, for example, pays the seller a premium at the beginning of the contract. In return, if the number of HDDs for the contract period is greater than the predetermined strike price the buyer will receive a payout. The amount of the payout is determined by the strike level and the tick amount (monetary value for each HDD exceeding the strike level of the option). The parameters of a typical weather option are:

- The contract type (call or put),

- The contract period (e.g. January 2006),

- The underlying index HDD or CDD,

- An official meteorological station from which the temperature data are extracted,

- The strike level,

- The tick amount (e.g. 5000 MAD/HDD),

- A maximum payout (if that exists).

To price the payout of an option, let denote $K$ the strike level and $\alpha$ the tick amount. Suppose that the contract consists of $n$ days. The HDDs and the CDDs for that period are, respectively

$$
H_{n}=\sum_{i=1}^{n} H D D_{i} \quad \text { and } \quad C_{n}=\sum_{i=1}^{n} C D D_{i}
$$

So, the formula of the payout of (an uncapped) HDD call is

$$
\chi=\alpha \max \left\{H_{n}-K, 0\right\}
$$

Another type of weather derivative contracts are swaps. Indeed, a swap is a contract in which two parties agree to exchange their risks during a predetermined period of time. In the most swaps contracts, the payments are made between two parties, where one pays a fixed price and the other a variable (or floating) one.

In the case of standard weather swaps, there is only one date where cash-flows are swapped contrary to interest rate swaps which have several dates of payment (Cf. Mraoua [28]).

In the case of a standard HDD swap, the two parties agree on a given strike level of HDDs over the period of the contract, and the amount swapped is, 
for example, $10000 \mathrm{MAD} / \mathrm{HDD}$ away from the strike. There is, in general, a maximum level of payout fixed at 200 degree-days.

To understand how the weather derivatives can be used in practice, we give the following example:

A heating gas distribution company may think, rightly, that if the winter is very cold, it will have significant incomes, therefore, it can think of selling a HDD call. If the winter is not particularly cold, the gas company keeps the premium of the call. If, on the other hand, the winter is very cold, the gas company will have enough money to finance the payout of the option which it emitted because its revenues would have been high. The gas company thus reduced its exposure to the weather risk.

\section{$3 \quad$ Weather dataset processing}

In this section, we will assess the clean of the meteorological data series of temperature. In one hand, this will be useful to estimate all the factors of the model used in this study and in the other hand, to determine the warm and the cold season during the year. In fact, we need that for evaluating the weather derivative contract.

\subsection{Filling the missing values}

For this research, we use daily average temperature data for the Casablanca weather station $\left(\mathrm{WMO}^{1} \mathrm{ID}: 60155\right)$. This data was computed from the extremes daily temperatures. The maximum and the minimum daily temperatures for the day $j$ are recorded at $2 \mathrm{~m}$ under shelter, respectively, between $j-1$ (yesterday) at $18 \mathrm{UTC}$ and $j$ at $18 \mathrm{UTC}$ for the minimum, and between $j$ at 06 UTC and $j+1$ (tomorrow) at $06 \mathrm{UTC}$ for the maximum.

The data series span from January 1960 to December 2003 (i.e. 44 years with 16071 observations). Obviously, there are few missing data (in our case, 92 missing values, i.e. $0.5 \%$ of the total available data, which are randomly distributed in time) which must be fixed before any treatment.

If there are missing observations in meteorological dataset, it will affect negatively all the post-treatment subroutines and then the rate of missing information will be as important as the number of omissions. In fact, weather data is vital to the success of weather risk management, and most weather derivatives pricing methodologies rely heavily on a "clean" weather dataset. According to Dunis and Karalis ([17]), the Principal Component Analysis method outperforms the other interpolation techniques and filling methods, like the Expectation Maximization (EM) algorithm, Neural Network Regression (NNR) models, the Data augmentation (DA) algorithm and the Kalman filter (KF).

Principal Component Analysis (PCA) is a statistical method for extracting the

\footnotetext{
${ }^{1}$ World Meteorological Organization
} 
most significant uncorrelated sources of variation in a multivariate system. The objective of PCA is to reduce dimensionality, so that only the most significant sources of information are used. This approach is very useful in highly correlated systems.

In our case, the missing values are distributed randomly in time as one, two, three and four consecutive observations. In order to evaluate the performance of PCA methodology, it was tested on clean sample of temperature data. The sample contains 573 observations (daily average temperature) for 11 variables (neighbouring weather stations). Then, missing data were created voluntary and artificially into the dataset (Table 1). These values are reconstructed using an iterative algorithm of PCA method. The different cases are treated separately.

\begin{tabular}{|c|c|c|c|}
\hline Observed value & Reconstituted value & Deviation & RMSE \\
\hline \multicolumn{4}{|c|}{1 value } \\
\hline 17.8 & 18.4 & 0.6 & 0.6 \\
\hline \multicolumn{4}{|c|}{2 consecutive values } \\
\hline 14.5 & 14.0 & -0.5 & \multirow[t]{2}{*}{0.35} \\
\hline 14.9 & 14.9 & 0.0 & \\
\hline \multicolumn{4}{|c|}{3 consecutive values } \\
\hline 21.8 & 21.3 & -0.5 & \multirow{3}{*}{0.40} \\
\hline 20.5 & 20.5 & 0.0 & \\
\hline 20.6 & $21.1=$ & 0.5 & \\
\hline \multicolumn{4}{|c|}{4 consecutive values } \\
\hline 16.6 & 16.7 र & 0.1 & \multirow{4}{*}{0.31} \\
\hline 15.4 & 16.0 & 0.6 & \\
\hline 15.9 & 16.0 & 0.1 & \\
\hline 16.6 & 16.7 & 0.1 & \\
\hline \multicolumn{4}{|c|}{7 consecutive values } \\
\hline 16.6 & 16.6 & 0.1 & \multirow{7}{*}{0.41} \\
\hline 15.4 & 16.0 & 0.6 & \\
\hline 15.9 & 16.0 & 0.1 & \\
\hline 15.9 & 16.0 & 0.1 & \\
\hline 16.3 & 15.4 & -0.9 & \\
\hline 14.8 & 14.7 & -0.1 & \\
\hline 16.0 & 16.0 & 0.0 & \\
\hline
\end{tabular}

Table 1: Reconstitution of missing data using the PCA method in case of one, two, three, four and seven consecutive missing observations

Table 1 shows that the imputations of daily mean temperature missing values obtained by PCA method are more accurate. We use the Root Mean Squared Error (RMSE) as standard error statistic to evaluate the deviation of the PCA results from the actual values for a missing days. The RMSE is given by

$$
R M S E=\sqrt{\frac{1}{N} \sum_{i=1}^{N}\left(x_{o b s}-x_{r e c}\right)^{2}}
$$

where $x_{o b s}$ and $x_{r e c}$ are respectively the observed and the reconstructed values. 
The RMSE error is often less than $0.6{ }^{\circ} \mathrm{C}$ which means that the accuracy of reconstitution is very important.

In order to be more realistic, the imputed values of the mean temperature dataset are compared to the actual values, taking into account the coexistence of the different cases of omissions, in the same dataset.

\begin{tabular}{||c|c|c|c|c||}
\hline $\begin{array}{c}\text { Obs } \\
\mathrm{N}^{\circ} .\end{array}$ & Date & $\begin{array}{c}\text { Observed } \\
\text { value }\end{array}$ & $\begin{array}{c}\text { Reconstituted } \\
\text { value }\end{array}$ & Deviation \\
\hline \hline 1 & $04 / 11 / 1999$ & 17.8 & 18.0 & 0.2 \\
2 & $19 / 11 / 1999$ & 14.5 & 13.9 & -0.6 \\
3 & $20 / 11 / 1999$ & 14.9 & 14.9 & 0.0 \\
4 & $21 / 01 / 2000$ & 10.6 & 11.0 & 0.4 \\
5 & $16 / 06 / 2000$ & 21.8 & 21.3 & -0.5 \\
6 & $17 / 06 / 2000$ & 20.5 & 20.5 & 0.0 \\
7 & $18 / 06 / 2000$ & 20.6 & 21.1 & 0.5 \\
8 & $22 / 12 / 2000$ & 14.0 & 14.4 & 0.4 \\
9 & $28 / 02 / 2001$ & 13.6 & 12.7 & -0.9 \\
10 & $13 / 03 / 2001$ & 16.6 & 16.7 & 0.1 \\
11 & $14 / 03 / 2001$ & 15.4 & 16.1 & 0.7 \\
12 & $03 / 04 / 2001$ & 17.3 & 17.3 & 0.0 \\
13 & $15 / 04 / 2001$ & 19.3 & 18.2 & -1.1 \\
14 & $16 / 04 / 2001$ & 16.3 & 16.7 & 0.4 \\
\hline
\end{tabular}

Table 2: Missing values artificially created in the test sample, their corresponding reconstituted values and the deviation between the two values

The mean of the RMSE error is null and its standard deviation is about $0.5^{\circ} \mathrm{C}$. Consequently, PCA provides a very efficient method for filling missing data in presence of correlated system of variables as it has been said before.

\subsection{The warm and the cold seasons at Casablanca}

In order to determine the warm and the cold periods during the year, we plot, on Figure 1, the monthly evolution of the monthly mean temperature over the period 1971-2000.

We notice that the warm period begins at the end of May and ends between October and November, the other period represents the cold one. A hierarchical ascendant classification was executed to define exactly the beginning and the end of each period. According to Figure 2, we have defined these periods as:

- Warm period: June to October

- Cold period: November to May 
Mohammed Mraoua, Driss Bari, Afrika Statistika, Vol.2, n¹, 2007, pp.22-43 Temperature Stochastic Modeling and Weather Derivatives Pricing : Empirical Study With Marrocan Data

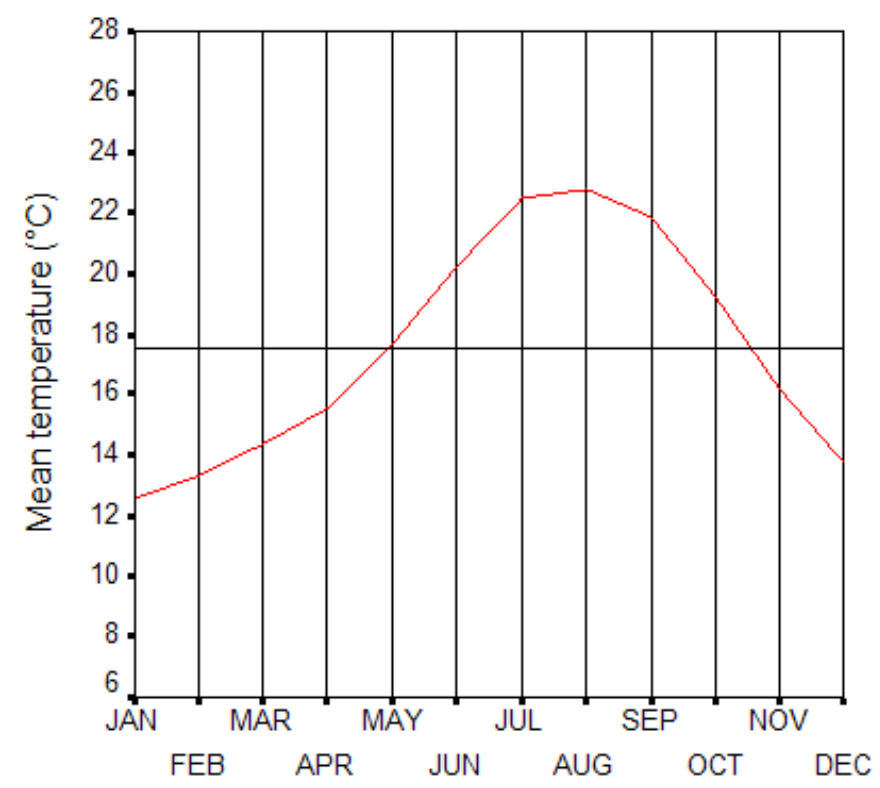

Figure 1: Monthly evolution of the monthly mean temperature at Casablanca $(1971-2000)$. $($ Mean $=17.8)$

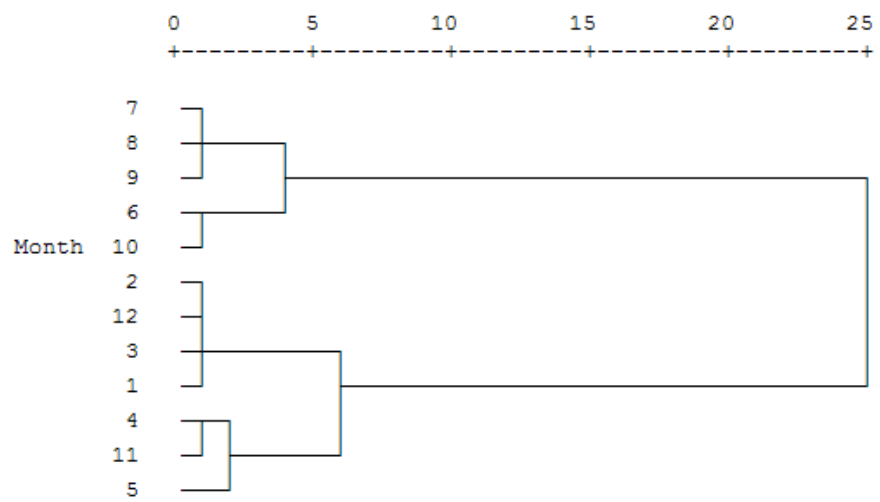

Figure 2: Hierarchical classification of the the monthly mean temperature at Casablanca (1971-2000) 


\section{Construction of temperature model}

The underlying variable of a weather derivative (temperature in our case) is a physical quantity rather than a tradable asset. This rules out the possibility of seeking an equivalent martingale approach to evaluate these derivatives owing to the fact that it is impossible to build an self financing strategy which can duplicate the underlying. Ideally, one would be to build a model of no-arbitrage as it is the case for interest rates derivatives. However, it exists no mechanisms which offer an outline on the world of no-arbitrage. Consequently, we will work in an equilibrium environment (Cf. Bhowan [8] and Alaton et al. [1]).

Since the mechanisms of valuation are based on equilibrium, there must be a strong influence of the historical data. Due to the cyclical nature of the temperature process, we find that historical data give a reasonable idea of the temperature level in the future (Cf. Figure 3).

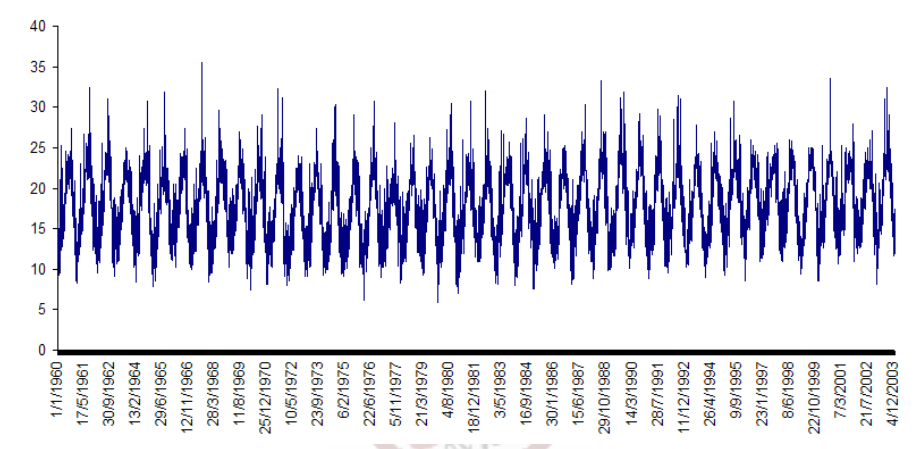

Figure 3: Daily temperature evolution for Casablanca meteorological station(January 1960-December 2003)

From Figure 3, it is clear that the temperature process should be a mean reverting process. The mean should have a cyclical form function. The histogram of daily temperature differences in Casablanca station is given by Figure 4.

The histogram on Figure 4 suggests a certain form of normal distribution of the daily temperature differences. Therefore, the temperature process should follow a Brownian motion.

We can use a Vasicek process with mean reversion to model the temperature behavior (this process is usually used as an interest rate model)

$$
d T_{t}=a\left(\theta-T_{t}\right) d t+\gamma d W_{t}
$$

where $T_{t}$ is the modeled process, $a$ the speed of mean reversion, $\theta$ the mean to which the process reverts to (constant) and $\gamma$ the volatility of the process (constant). $d W_{t}$ is a Wienner process.

Now, for the temperature process, we need a $\theta=\theta(t)$ and a $\gamma=\gamma(t)$ (function which changes monthly, for the moment). 


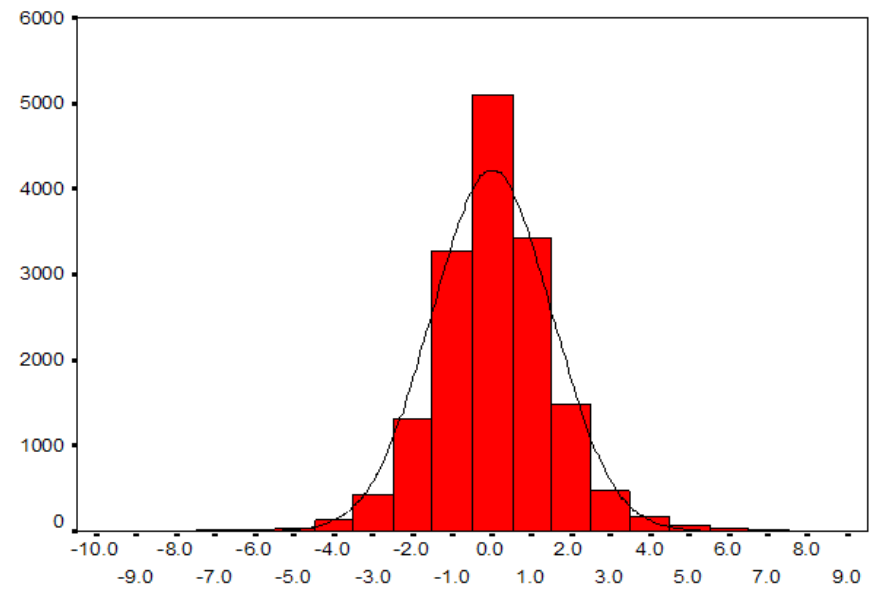

Figure 4: Daily temperature differences Histogram for Casablanca-Anfa meteorological station (January 1960-December 2003)

Then, our process becomes

$$
d T_{t}=a\left(\theta_{t}-T_{t}\right) d t+\gamma_{t} d W_{t}
$$

A functional form of $\theta$ needs to be determined and estimation for $\gamma$ and $a$ should be calculated on the basis of historical data. In order to have a process that reverts to its mean, it would be necessary that one has

$$
E\left[T_{t}\right] \approx \theta_{t}
$$

Dornier and Queruel ([16]) showed that the process found in (8) does not checked by (9), from where the idea according to Dornier and Queruel [16] and Bhowan [8] to add the $\theta_{t}^{\prime}$ term to the process (8).

Proposition If $\theta=\theta(t)$, then the process

$$
d T_{t}=\left[a\left(\theta_{t}-T_{t}\right)+\frac{d \theta}{d t}\right] d t+\gamma_{t} d W_{t}
$$

reverts to its mean $\theta$.

Proof (from Dornier and Queruel [16]) Let consider $Z_{t}=e^{\int_{0}^{t} a d_{s}}\left(\theta_{t}-T_{t}\right)$

According to Itô lemma, we can write

$$
\begin{aligned}
d Z_{t} & =e^{\int_{0}^{t} a d_{s}} \theta_{t}^{\prime} d t+a e^{t}\left(\theta_{t}-T_{t}\right) d t-e^{\int_{0}^{t} a d_{s}} d T \\
& =e^{\int_{0}^{t} a d_{s}}\left[\theta_{t}^{\prime}+a\left(\theta_{t}-T_{t}\right) d t-\left(a\left(\theta_{t}-T_{t}\right)+\theta_{t}^{\prime}\right) d t-\gamma_{t} d W_{t}\right]
\end{aligned}
$$


Thus, we find

$$
Z_{t}=Z_{0}-\int_{0}^{t} e^{\int_{0}^{t} a d s} \gamma_{s} d W_{s}
$$

Now, $\theta_{0}=T_{0}=C$ gives

$$
T_{t}=\theta_{t}+e^{-\int_{0}^{t} a d s} \int_{0}^{t} e^{\int_{0}^{t} a d s} \gamma_{s} d W_{s}
$$

So $E\left[T_{t}\right]=\theta_{t}$ (because an Itô integral has a zero expected value ).

According to the graph of Figure 3, we can adjust to the mean $\theta$, the functional given by the equation

$$
\theta_{t}=A+B t+C \sin (\omega t+\varphi)
$$

where $\omega=\frac{2 \pi}{365}$ (we will not consider the leap years).

To be able to simulate trajectories by using the model described in (10), we need to estimate its parameters.

\subsection{Estimation of mean parameters $A, B, C, \varphi$}

From (13), we can write $\theta(t)$ under the following form

$$
\theta(t)=A+B t+C[\sin (\omega t) \cos (\varphi)+\cos (\omega t) \sin (\varphi)]
$$

Then, it is possible to estimate the parameters of the equation (14) by looking it like a linear equation of time by operating some changes of variables and by renaming the constants. We can then write

$$
\theta(t)=\beta_{1}+\beta_{2} t+\beta_{3} \sin (\omega t)+\beta_{4} \cos (\omega t)
$$

where

$$
\left\{\begin{aligned}
A & =\beta_{1} \\
B & =\beta_{2} \\
\varphi & =\tan ^{-1}\left(\frac{\beta_{4}}{\beta_{3}}\right) \\
C & =\frac{\beta_{3}}{\cos (\varphi)}
\end{aligned}\right.
$$

By applying the least squares method to the series of the 16060 observations of the historic daily temperatures, we find 


$$
\left\{\begin{aligned}
A & =17.1113 \\
B & =0.000070201 \\
\varphi & =-4.9956 \\
C & =0.978
\end{aligned}\right.
$$

The graph of Figure 5 makes possible to visualize a comparison between the observed temperatures and those estimated by using the deterministic approach given by $\theta(t)$. For a good visualization of the behavior of the two curves, we plotted only the first ten years of our series of observations.

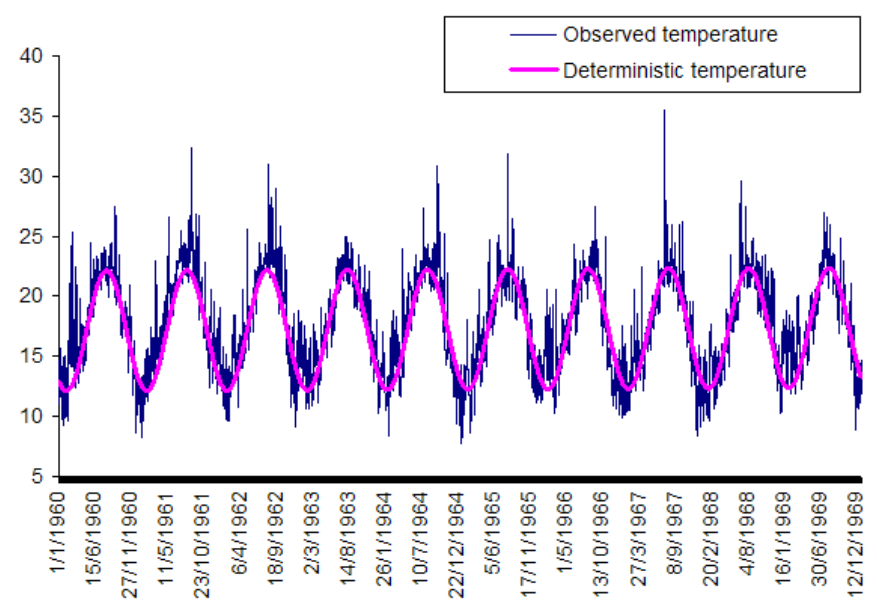

Figure 5: Comparison between historic temperature and the estimated mean $\theta(t)$. Casablanca-Anfa meteorological station (01/01/1960-31/12/1969)

\subsection{Estimation of speed of mean reversion $a$}

According to Bhowan ([8]), if

$$
d X_{t}=b\left(X_{t} ; \xi\right) d t+\sigma\left(X_{t} ; \xi\right) d W_{t}
$$

then, an unbiased estimator of $\xi$ is the zero of the martingale function given by

$$
G_{n}(\xi)=\sum_{i=1}^{n} \frac{\dot{b}\left(X_{(i-1) \Delta} ; \xi\right)}{\sigma^{2}\left(X_{(i-1) \Delta} ; \xi\right)}\left[X_{i \Delta}-E\left[X_{i} \mid X_{i-1}\right]\right]
$$

where $\dot{b}=\frac{\partial b}{\partial \xi}$

Therefore, if we take again the process developed in (10), and we make integration between $i$ and $(i-1)$, we find 


$$
T_{i}=\theta_{i}+e^{-a}\left(T_{i-1}-\theta_{i-1}\right)+e^{-\int_{0}^{i} a d s} \int_{i-1}^{i} e^{\int_{0}^{s} a d s} \gamma_{s} d W_{s}
$$

And as

$$
E\left[T_{i} \mid T_{i-1}\right]=\theta_{i}+e^{-a}\left(T_{i-1}-\theta_{i-1}\right)
$$

By substituting in (17), we find

$$
G_{n}(\xi)=\sum_{i=1}^{n} \frac{\left(\theta_{i-1}-T_{i-1}\right)}{\gamma_{i-1}^{2}}\left[T_{i}-\theta_{i}-e^{-a}\left(T_{i-1}-\theta_{i-1}\right)\right]
$$

Solving (20) gives

$$
a=-\log \left(\frac{\sum_{i=1}^{n} \frac{\left(T_{i-1}-\theta_{i-1}\right)}{\gamma_{i-1}^{2}}\left(T_{i}-\theta_{i}\right)}{\sum_{i=1}^{n} \frac{\left(T_{i-1}-\theta_{i-1}\right)}{\gamma_{i-1}^{2}}\left(T_{i-1-\theta_{i-1}}\right)}\right)
$$

By performing the calculation in (21), we find $a=0.274750728$.

\subsection{Estimation of the volatility}

Alaton et al. [1], suppose that the volatility of the temperature process varies through different months, but it remains nearly constant within each month. Consequently, $\gamma_{t}$ is seen as a constant function which changes monthly.

In this article, we will use the approach developed by Bhowan ([8]), where the volatility is regarded as a stochastic process. We calculated and plotted the graph of the monthly standard-deviations of our dataset. We will consider a stochastic process with mean reversion (Cf. Figure 6).

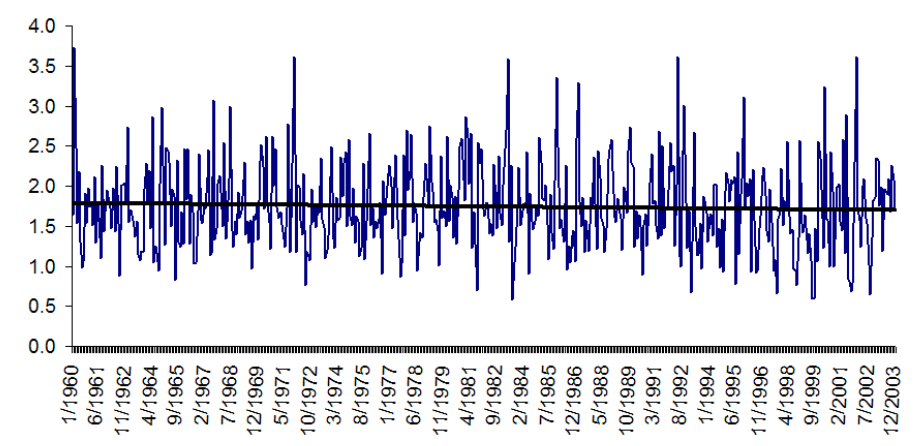

Figure 6: Monthly volatility of observed temperatures with linear trend. Casablanca-Anfa (January 1960-December 2003) 
The stochastic differential equation of the volatility process has the following form

$$
d \gamma_{t}=a_{\gamma}\left(\gamma_{\text {trend }}-\gamma_{t}\right) d t+\sigma_{\gamma} d W_{t}
$$

By supposing that $\gamma_{\text {trend }}$ is constant (Cf. Figure 4), it remains to estimate $a_{\gamma}$ and $\sigma_{\gamma}$. If we use the estimator presented in Alaton et al. [1], we get

$$
\sigma_{\gamma}^{2}=\frac{1}{n} \sum_{j=0}^{n-1}\left(\gamma_{j+1}-\gamma_{j}\right)^{2}
$$

where $n$ is the number of observations.

Performing the calculation give $\sigma_{\gamma}=0.7078984$.

To estimate $a_{\gamma}$, we will use the methodology developed in the previous section. Since $\gamma_{\text {trend }}$ is constant, we can rewrite the process in the following form

$$
\begin{aligned}
d \gamma_{t} & =a_{\gamma}\left(\gamma_{\text {trend }}-\gamma_{t}\right) d t+\sigma_{\gamma} d W_{t} \\
& =\left[a_{\gamma}\left(\gamma_{\text {trend }}-\gamma_{t}\right)+\frac{d \gamma_{\text {trend }}}{d t}\right] d t+\sigma_{\gamma} d W_{t}
\end{aligned}
$$

Then

$$
E\left[\gamma_{i} \mid \gamma_{i-1}\right]=\gamma_{\text {trend }}+e^{-a}\left(\gamma_{i-1}-\gamma_{\text {trend }}\right)
$$

Hence, $a_{\gamma}$ is given by

$$
a_{\gamma}=-\log \left(\frac{\sum_{i=1}^{n} \frac{\left(\gamma_{\text {trend }}-\gamma_{i-1}\right)}{\sigma_{\gamma}^{2}}\left(\gamma_{i}-\gamma_{\text {trend }}\right)}{\sum_{i=1}^{n} \frac{\left(\gamma_{\text {trend }}-\gamma_{i-1}\right)}{\sigma_{\gamma}^{2}}\left(\gamma_{i-1}-\gamma_{\text {trend }}\right)}\right)
$$

Performing the calculation gives $a_{\gamma}=1.85275425$.

\subsection{Processus Simulation}

In order to simulate sample paths of temperature, (10) and (22) need to be discretised. Using the Euler scheme of approximation, we get

$$
\begin{gathered}
T_{t+1}=T_{t}+a\left(\theta_{t}-T_{t}\right)+\theta_{t}^{\prime}+\gamma_{n} Z_{1} \\
\gamma_{n}=\gamma_{n-1}+a_{\gamma}\left(\gamma_{\text {trend }}-\gamma_{n-1}\right)+\sigma_{\gamma} Z_{2}
\end{gathered}
$$


where $Z_{1}, Z_{1} \sim N(0,1)$.

for each month, $\gamma_{n}$ is simulated using (26), the simulated $\gamma_{n}$ is then used in (25) for an entire month simulation. Figure 7 gives on the same diagram the evolution over three years (of 2004 to 2006) of a simulated trajectory of the estimated temperature and its mean $\theta(t)$.

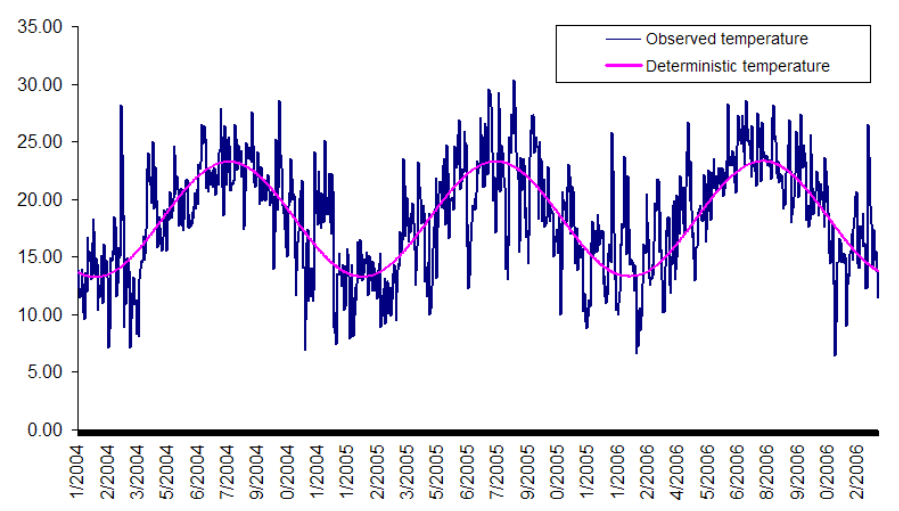

Figure 7: Simulation of sample paths of temperature and the mean over 3 years estimated by using the Euler scheme (2004-2006)

\subsection{Validation of the model}

In this section, we compare the predicted values obtained by the stochastic model to the actual observations for Casablanca over the year 2004 (Cf. Figure 8).

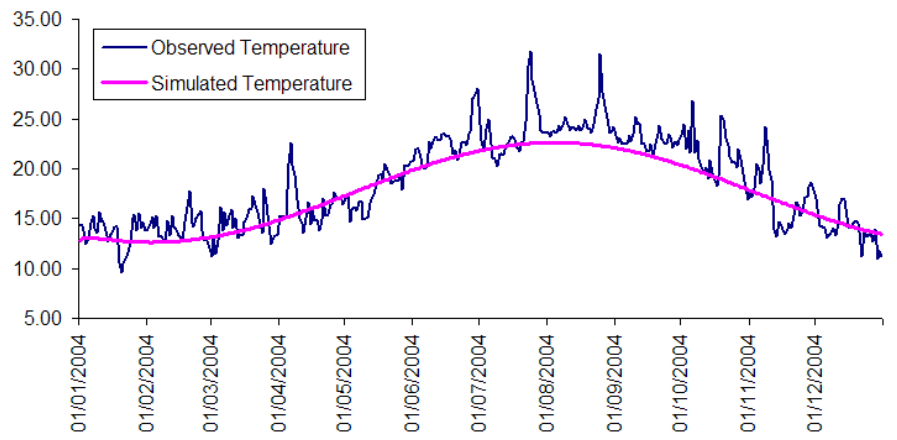

Figure 8: Observed temperatures and simulated temperature with 200000 simulations (Casablanca-Anfa : 2004)

In order to evaluate the performance of the model, we use the relative error as a statistical error. It is given by the formula 


$$
R E=\frac{T_{p r e v}-T_{o b s}}{T_{o b s}}
$$

where $T_{\text {prev }}$ and $T_{\text {obs }}$ refer respectively to the predicted and the observed values.

On the daily scale, many "aberrations" were detected in the temporal evolution of the normalized relative error, which are often due the Chergui ${ }^{2}$ phenomenon. Actually, this phenomenon presents some daily lifts which "escaped" to the model. Therefore, we have tested the model for the monthly average temperatures. The fact that the weather derivatives are often concluded over a monthly periods, justify in other way our choice.

In Figure 9, the monthly evolution of the normalized relative error shows that this error belongs to the interval $[-1,+1]$ with two jumps on May and December. They represent the transitions between the warm and cold periods defined before.

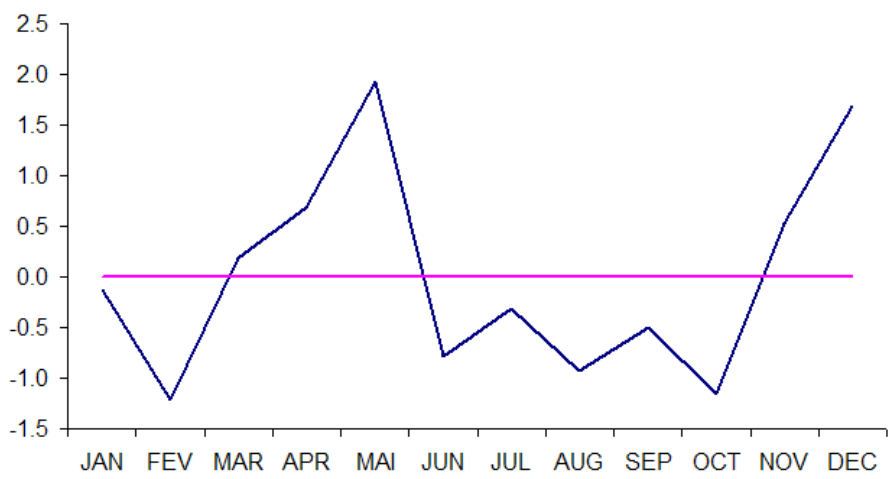

Figure 9: Monthly evolution of the standardized relative error (2004)

In term of Standardized Relative Error (SRE), we can say that our model forecasts the temperature correctly.

\section{$5 \quad$ Weather swap pricing}

Let us consider two parts A and B. A is an electricity distribution company and $\mathrm{B}$ is a large refreshment beverage producer. A profits from a cold weather (rise of the demand of electricity for the heating) and B benefits from a warm weather (increase in the consumption of refreshment drinks). The two parts seek to stabilize their incomes flows.

Let us consider the following contract:

- Contract period: from $01 / 01 / 2004$ to $12 / 31 / 2004$

\footnotetext{
${ }^{2}$ Dried wind and warm flow, blowing from the East of Morocco.
} 
- Reference temperature degree $\left(T_{\text {ref }}\right): 18^{\circ} \mathrm{C}$

- Principal Nominal $\left(N_{p}\right)$ : $1000 \mathrm{MAD}$

The choice of the reference temperature degree is strongly depending on the location. In our case, the average as well as the median of the time series used are about $17.8^{\circ} \mathrm{C}$, which pushed us to take the value $18^{\circ} \mathrm{C}$ like threshold of reference in the calculation of CDD and HDD.

As A benefits from a cold weather, its incomes are maximum during the period November-May. In a similar way, the incomes of B are maximum for the period June-October. Consequently, we have the degree-days and the following strike levels for each month of 2004 (Cf. Table 3).

\begin{tabular}{||l|c|c||}
\hline Month & Index & Strike \\
\hline \hline January & HDD & 160 \\
February & HDD & 45 \\
March & HDD & 90 \\
April & HDD & 35 \\
May & HDD & 85 \\
June & CDD & 100 \\
July & CDD & 200 \\
August & CDD & 170 \\
September & CDD & 30 \\
October & CDD & 60 \\
November & HDD & 90 \\
December & HDD & 160 \\
\hline
\end{tabular}

Table 3: Underlying indexes and strike levels for the 12 months of 2004 (contrat period)

At the end of each month, if the degree-day is CDD, B gives a payment to A. So on the other hand, the measurement is HDD, then it is A which gives a payment to B. The measured degree-days must be lower than the strike levels for each month.

By using, (2), (3) and (4), we can write

$\operatorname{Value}_{B}(01 / 01 / 2004)$

$$
\begin{aligned}
& =N_{p}\left\{\sum_{i \in C S} E[\max (H(i)-K(i), 0)-\max (K(i)-H(i), 0)] B\left(0, i_{\text {month }}\right)\right. \\
& \left.+\sum_{j \in W S} E[\max (K(j)-C(j), 0)-\max (C(j)-K(j), 0)] B\left(0, j_{\text {month }}\right)\right\}
\end{aligned}
$$

where

- $K(i)$ is the strike level of the month $i$, 
- $C S$ is the set of cold season months (in our study, from November to May),

- $W S$ is the set of warm season months (in our study, from Jun to October),

- $B\left(0, i_{\text {month }}\right)$ is the discount rate for the month $i$.

The swap is then a sequence of collars. In order to evaluate the formula giving Value $_{B}(01 / 01 / 2004)$, we simulate the trajectories of the temperature over the swap period like that was described previously. Thereafter, we carry out the evaluation of the swap by the calculation of the average of the payments which are generated by the simulation trajectories (valuation according to the Monte Carlo method).

If we make the assumption of a discount interest rates equals to (8\%) and we makes 90000 simulations, we find

$$
\begin{aligned}
\operatorname{Value}_{B}(01 / 01 / 2004) & =N_{p} \times 69.060 \\
& =69060 \mathrm{MAD}
\end{aligned}
$$

From Figure 10, we remark that the convergence of the swap price is very slow.

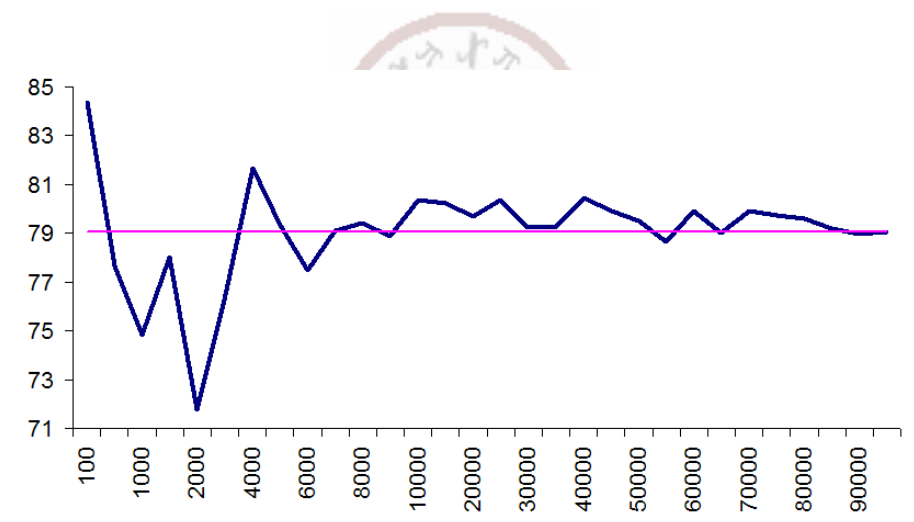

Figure 10: Monte Carlo convergence of the swap price and the simulations convergence trend

\section{Conclusions and topics for further research}

Weather derivatives are highly structured financial products. They allow a dynamic management of the weather risk and constitute a good instrument to diversify the financial portfolios (in fact of the non correlation, in general, between weather and financial markets). Moreover, and contrary to the traditional products of insurance against the weather disasters, the financial products based on weather allow companies either to be covered against climatic risks and also to make profit by speculation (Moreno [25]). 
The use of the derivatives in Morocco is still very limited, but the weather derivatives could constitute a good instrument to cover against climatic risk. These risks from which Morocco suffers these last years (lengthening of the periods of dryness and freezing, floods, etc.) weigh heavily on the economy of the country (Gauvin [19]).

In this study, we worked on a stochastic modeling to describe the behavior of the temperature which we chose as underlying for the weather derivative product described in this article. Other approaches to valuation of weather derivatives are used in practice as the actuarial approach or the "Burn Analysis" method (Cao and Wei [11] and Moreno [24]).

The determination of the cold and warm seasons, on the basis of 44 year of data of temperature, in Casablanca and which correspond respectively to the periods of November-May and June-October, enabled us to simulate a swap contract on temperature. The valuation of this contract was carried out using a temperature stochastic model. The model parameters were estimated using daily temperature data (1960-2003). The reference temperature degree which is a key parameter of the determination of HDD and CDD and which strongly depends on the local conditions of the site to which relates the climatic contract, was calculated statistically using the dataset of Casablanca.s

The model describing the stochastic behavior of the temperature was validated on the basis of temperature observed during the year 2004. The results of comparison of the forecasts (outputs of the model) to the observations are satisfactory.

It would be interesting to treat carefully the jumps of temperatures due to the extreme phenomena (for example Chergui wind) by integrating a term which describes their behavior within the stochastic model. This will make it possible to improve the performance of the daily scale model.

\section{Acknowledgments}

The authors acknowledge the helpful comments of Zouhair LACHKAR (Researcher at the French Atomic Energy Commission).

Computations were made with MATLAB and MS Excel software.

The views expressed here are solely the authors' and are not those of the organizations where they work. All remaining errors are ours.

\section{References}

[1] Alaton, P., Djehiche, B. and Stillberger, D. (2002), "On Modelling and Pricing Weather Derivatives", Applied Mathematical Finance, Volume 9, Issue 1. 
[2] Augros, J.- C. and Queruel, M. (2001), "Les dérivés climatiques et naturels : de nouvelles opportunités pour les investisseurs", ISFA, Université de Claude Bernard Lyon 1 and CDC IXIS Capital Markets, July.

[3] Barrieu, P. and El Karoui, N. (2004), "Présentation générale des dérivés climatiques", London School of Economics, Statistics Department and Ecole Polytechnique, CMAP, January.

[4] Ben Salem-Hajili, A. (2005), "Dérivés climatiques : Approche de modélisation longue mémoire pour l'étude et l'analyse d'un sous-jacent météorologique (la température)", Working paper, Centre d'économie mathématique, d'économétrie, de la finance et de la gestion, Université Panthéon-Assas, Paris.

[5] Benth, F. E. (2004), "A stochastic temperature dynamics with applications to weather derivatives pricing", Center of Mathematics for Applications, Oslo, December.

[6] Benth, F. E. and Saltyte-Benth, J. (2004), "Stochastic Modelling of Temperature Variations with a view towards Weather Derivatives", Statistical Research Report, Department of Mathematics, University of Oslo, January.

[7] Benth, F. E. and Saltyte-Benth, J. (2005), "The Volatility of Temperature and Pricing of Weather Derivatives", Centre of Mathematics for Applications, Oslo, March.

[8] Bhowan, A. (2003), "Temperature Derivatives", School of Computational and Applied Mathematics, University of Wiwatersrand, January.

[9] Campbell, S. D. and Diebold, F. X. (2002), "Weather Forecasting for Weather Derivatives", Wharton, The Rodney L. White Center for Financial Research, December.

[10] Campbell, S. D. and Diebold, F. X. (2002), "Weather Forecasting for Weather Derivatives", Journal of the American Statistical Association, Vol. 100, No. 469, Applications and Case Studies, March.

[11] Cao, M., Li, A. and Wei, J. (2003), "Weather Derivatives: A new Class of Financial Instruments", York University, XL Weather \& Energy Inc., Stamford and University of Toronto, April.

[12] Cao, M., Li, A. and Wei, J. (2004), "Precipitation Modelling and Contract Valuation: A Frontier in Weather Derivatives", The Journal of Alternative Investments, Automne.

[13] Chaumont, S., Imkeller, P., Müller, M. and Horst, U. (2005), "A simple model for trading climate risk", Institut für Mathematik, Humboldt- Universität zu Berlin and Department of Mathematics, University of British Columbia, March.

[14] Considine, G. (2000), "Introduction to Weather Derivatives", Weather Derivatives Group, Aquila Energy.

[15] Davis, M. (2001), "Caution to the wind", Weather Risk Special Report, Risk, Energy \& Power Risk Management, August. 
[16] Dornier, F. and Querel, M. (2000), "Pricing weather derivatives by marginal value", Quantitative Finance, Volume 1, Institute of Physics Publishing.

[17] Dunis, C. L. and Karalis, V. (2003), "Weather Derivatives Pricing and Filling Analysis for Missing Temperature Data", Liverpool Business School \& CIBEF, January.

[18] Garman, M., Blanco, C. and Erickson, R. (2000), "Weather Derivatives: Instruments and Pricing Issues", Environmental Finance, March.

[19] Gauvin, A. (2003), "Les enjeux des produits dérivés pour le Maroc", L'Economiste, November.

[20] Hull, J. C. (1997), "Options, Futures and Other Derivatives", Prentice Hall.

[21] Jewson, S. and Caballero, R. (2003), "Seasonality in the statistics of surface air temperature and the pricing of weather derivatives", Meteorol. Appl.

[22] Jewson, S. et Caballero, R. (2003), "The use of weather forecasts in the pricing of weather derivatives", Meteorol. Appl.

[23] Karia, T. (2003), "Weather Risk Swap Valuation", Research Centre for Financial Engineering, Institute of Economic Research, Kyoto, April.

[24] Moreno, M. (2000), "Evaluation des dérivés climatiques”, ISFA, Université de Claude Bernard Lyon 1.

[25] Moreno, M. (2000), "Dérivés climatiques-Organisation du marché de gré à gré et techniques d'évaluation", ISFA, Université de Claude Bernard Lyon 1.

[26] Moreno, M. (2000), "Riding the Temp", FOW, Special Supplement Weather Derivatives, December.

[27] Moreno, M. (2003), "Weather derivatives hedging and swap illiquidity", WRMA, June.

[28] Mraoua, M. (2002), "Mise en place d'un pricer de swaps de taux court terme au Maroc", PFE, INSEA, June.

[29] Mraoua, M. (2004), "Les Swaps de volatilité : valorisation et application au marché financier marocain", Revue de l'INSEA, 21 : 121- 134.

[30] Müller, A. and Grandi, M. (2000), "Weather Derivatives-Finding cover from the weather", Technical Report, Financial Reinsurance/ART Division of Munich Reinsurance Company.

[31] Platen, E. and West, J. (2004), "Fair Pricing of Weather Derivatives", School of Finance \& Economics and Department of Mathematical Sciences, University of Technology, Sydney, July.

[32] Randalls, S. (2004), "Weather, Finance and Meteorology: Forecasting and Derivatives", School of Geography, Earth and Environmental Sciences, University of Birmingham. 
Mohammed Mraoua, Driss Bari, Afrika Statistika, Vol.2, n¹, 2007, pp.22-43 Temperature Stochastic Modeling and Weather Derivatives Pricing : Empirical Study With Marrocan Data

[33] Roustand, O., Lauren, J.- P., Buy, X. and Carraro, L. (2003), "A Bootstrap approach to price uncertainty of weather derivatives", Ecole des Mines, Saint-Etienne and Ecole ISFA, Villeurbanne, December.

[34] Roustand, O., Laurent, J.- P., Bay, X. and Carraro, L. (2003), "Model Risk in the Pricing of Weather Derivatives", Ecole des Mines, Saint- Etienne and Ecole ISFA, Villeurbanne, September.

[35] Yoo, S. (2003), "Weather Derivatives and Seasonal Forecast", Cornell University, Ithaca, New York, January.

[36] Zeng, L. (2000), "Pricing Weather Derivatives", Technical Report, Blanch Company, Minneapolis, Spring. 